
\title{
25 Research Square \\ Public Trust in Healthcare System and Its Correlates during the COVID-19 Epidemic in Iran
}

\section{Hossein Molavi Vardanjani}

Health policy Research Center, Institute of Health, Shiraz University of Medical Sciences, Shiraz, Iran

Mohammad-Hadi Imanieh

Shiraz University of Medical Sciences

Amir-Hossein Hassani

Shiraz University of Medical Sciences

Kamran Bagheri-Lankarani ( $\sim$ kblankarani@yahoo.com )

Health policy Research Center, Institute of Health, Shiraz University of Medical Sciences, Shiraz, Iran

\section{Research Article}

Keywords: Public, trust, Healthcare System, COVID-19, Epidemic, Iran

Posted Date: November 12th, 2020

DOI: https://doi.org/10.21203/rs.3.rs-106242/v1

License: (c) (1) This work is licensed under a Creative Commons Attribution 4.0 International License. Read Full License 


\section{Abstract}

Background: Public trust in the healthcare system is a critical necessity of management in public health crises such as the COVID-19 pandemic. To rapidly assess the public trust in the healthcare system during the COVID-19 epidemic and its correlates in Iran.

Methods: A cross-sectional rapid assessment was conducted in Iran during the COVID-19 epidemic in the country. A probability proportional to size multistage random sampling was applied. Sampling was done in 15 provinces. We collected data on public perceived fear, public trust in health system and sociodemographics. Ordinary least square regression modeling was applied to identify correlates of public trust.

Results: A total of 5250 adults (response rate: $76 \%$ ) were participated in the study. Mean of reported trust scores was $50.3 \pm 22.8$, and of fear scores was $72.0 \pm 17.8$. Being male $(p=0.006)$, higher levels of education $(p<0.001)$ and socio-economic status $(p<0.001)$, and higher fear scores $(p<0.001)$ were independently correlated with trust in healthcare system.

Conclusion: At the time of the COVID-19 epidemic in Iran, public trust in healthcare system is low. A dynamic public epidemic communication with appropriate strategies to communicate with higher social classes is urgent in Iran. Rapid assessments to identify appropriate strategies are needed. These results might be generalizable to the other similar countries during the COVID-19 pandemic.

\section{Background}

Public trust in the healthcare system is a critical necessity of management in public health crises such as the COVID-19 pandemic[1]. At the same time as public health crises, the healthcare system usually struggles with at least two serious challenges. One is the uncertainty caused by the lack of evidence, and the other is the high number of destructive rumors being propagated[2]. The combination of these two challenges can lead to a devastating public panic, a situation that could lead to severe disruption of social functions and eventually more complicated conditions and even failure of crisis control efforts[3].

Over time, public health policymakers have to make new decisions based on new scientific evidence or refine their previous statements[4, 5]. It may contribute to a crisis of public uncertainty. On the other hand, different available sources of information can amplify both challenges of public panic and uncertainty[3, $6]$.

Scientific evidence suggests that a tailored public epidemic communication can greatly help control these challenges[7]. At the same time, however, as public health policymakers' decisions are not always simple and low-cost, such as hand washing, they need public trust in the healthcare system, a psychological state in which people believe that the values of their healthcare system are the similar to those of them, and it has adequate competencies and abilities to control the crisis, and to actively work to provide the 
best services to the public[8]. Public trust in the healthcare system is the upstream root of public support for health policymakers' decisions and compliance with crisis control measures[9].

Public trust in the healthcare system is rooted in various distant and near-term factors. It is recognized as a multidimensional issue [4, 8-10]. Factors such as socioeconomic status, ethnicity, place of residence, current health status, people's past experiences with the healthcare system, media, and economic status of the community are some of the correlates of such trust [4, 8-10]. In addition, the healthcare system's actions targeted towards a health crisis can weaken or enhance public trust in the healthcare system[11, 12]. In pervasive crises, it can be argued that subgroups with less trust in the healthcare system may be at greater risk; as a result, identification of these at risk subgroups is necessary [13].

Despite the acceptable quality of Iranian healthcare services[14], the Iranian healthcare system has been facing serious challenges that hinder it being fully prepared to deal with crises such as COVID-19 epidemic. A few of those challenges include high and an ever-increasing number of medical scandals propagated in the media alongside a shortage of medicines due to the economic conditions caused by sanctions posed by the United States in recent years[15].

Moreover, many rumors have been propagated through social networks and other sources since the instant of public announcement regarding the start of the COVID-19 epidemic in Iran. The COVID-19 attributed mortality rates in Iran are higher than in other parts of the world[2], some experts or political groups oppose the healthcare system's decisions to control the epidemic; and some extremist groups ridicule the healthcare system's recommendations. These conditions can severely damage public trust in the healthcare system.

This rapid assessment aimed to investigate the level of public trust in the health system and its correlates during the COVID-19 epidemic in Iran.

\section{Methods}

A cross-sectional study was conducted in Iran during the COVID-19 epidemic in the country. Iranian adults, aged 18 to 60 years, who were able to read in Persian and work with smartphones were considered eligible to participate in this study.

Assuming a rate of $30 \%$ for trust in the healthcare system in Iran, type I error of $5 \%$, a probability proportional to size (PPS) multistage cluster random sampling within 15 provinces, a design effect of two, and a rate of $40 \%$ of non-response, a sample size of 6930 was calculated for the study.

Random digit dialing was done using fixed phone numbers. Selected numbers were called, and the study aim and its procedures were explained for those who were on the phone. Then, they were asked whether they were interested to participate in the study or not. If they accepted to participate, we shared the link of the study questionnaire with them via their cell phone numbers. 
First phone calls were made by trained nurses. After an interim analysis, sampling was continued until completion of predefined samples in all age-gender strata.

Considering contextual issues, in order to increase the participation rate, and also collect more accurate responses, we had to use a very short questionnaire (15 questions) for data collection. Accordingly, data on age, gender, educational level, ethnicity, province of residence, the population in the area of residence, and the main source of information about COVID-19 were collected. To measure socioeconomic status (SES), we used a short form that was validated for use in Iran to collect data on participants' assets[16]. Level of trust in the healthcare system and perceived fear of COVID-19 were measured using two visual analog scales (VAS), inspired with method had applied by zhao et. al.[17]. Each VAS was ranged from zero to 100. We defined trust and fear for participants initially, then asked them to rate their trust in the healthcare system and their perceived fear. The definition of trust was "a state in which you are sure that Iran's ministry of health has adequate ability and competency to control the COVID-19 epidemic in Iran, and it is trying to do this with its bests". And the definition of the highest level of fear was as "a state in which you worry that the life of yourself and your loved ones is threatened by COVID-19 always and every day; therefore, you are unable to do anything".

This study was approved by the ethics committee of Shiraz University of Medical Sciences. We also adhere to the principles of the Helsinki Declaration on principles of biomedical research ethics.

Statistical analysis

To estimate the rank of participants in case of socioeconomic status (SES), we conducted an assets analysis using multiple correspondence analysis (MCA). The estimated latent factor was categorized into its deciles. Univariate analysis was done applying two independent sample t-test, and one-way analysis of variance (ANOVA). Pearson correlation coefficient estimated to measure the linear correlation of trust and fear scores. Multiple ordinary least square linear regression was applied to identify the correlates of trust in the healthcare system. We adjusted our regression modeling for the clustering nature of the data. As the sampling was done in a probability proportional to size design no weight was applied for data analysis. Crude and adjusted regression coefficients (RC) and their $95 \%$ confidence intervals ( $\mathrm{Cl}$ ) were estimated. A P-value of less than 0.05 was considered statistically significant. Data analysis was done using Stata software (release 11.2; StataCorp LP: College Station, TX, US).

\section{Results}

Response rate was 76\% (5250 completed forms out of 6930 shared links). 50.5\% ( $n=2653$ ) of the study participants were female with a mean age of $38.9 \pm 12.4$ years, and $49.5 \%(n=2598)$ were male with a mean age of $39.2 \pm S D=12.5$. Mean score of public trust in the healthcare system was estimated as $50.3 \pm 22.8$, and estimated mean score of perceived fear of COVID-19 was $72.0 \pm 17.8$ (Table 1).

Table 1. Iranian Public Trust in Healthcare System during the COVID-19 Epidemic by Their Characteristics 


\begin{tabular}{|c|c|c|c|}
\hline Characteristics & No. of Participants (\%) & Trust, Mean (SD) & P-value \\
\hline \multicolumn{4}{|l|}{ Gender } \\
\hline Male & $2598(49.5)$ & 49.5(24.1) & \multirow[t]{2}{*}{0.012} \\
\hline Female & 2653(50.5) & $51.1(21.3)$ & \\
\hline \multicolumn{4}{|l|}{ Educational level } \\
\hline Less than Diploma & $214(4.1)$ & $55.2(26.8)$ & \multirow[t]{5}{*}{$>0.001$} \\
\hline $\mathrm{AE} 1^{*}$ & $861(16.4)$ & $52.0(22.6)$ & \\
\hline AE 2 & 1869(36.1) & $50.2(22.4)$ & \\
\hline AE 3 & 1724(32.8) & $49.9(21.0)$ & \\
\hline AE 4 & $556(10.6)$ & $46.5(22.7)$ & \\
\hline \multicolumn{4}{|c|}{ Population of the area of residence (in 1000) } \\
\hline Less than 100 & 1157(22.0) & $51.4(23.3)$ & \multirow[t]{4}{*}{0.049} \\
\hline 100 to 500 & $707(13.5)$ & $51.2(22.2)$ & \\
\hline $500-1000$ & $1228(23.4)$ & $49.3(23.2)$ & \\
\hline More than 1000 & 2159(41.1) & 49.6(23.0) & \\
\hline \multicolumn{4}{|c|}{ Main source of information about COVID-19 } \\
\hline Agencies inside Iran & 3699(70.4) & $51.9(22.6)$ & \multirow[t]{2}{*}{$>0.001$} \\
\hline Agencies outside Iran & 1552(29.6) & $46.7(21.6)$ & \\
\hline \multicolumn{4}{|l|}{ Ethnicity } \\
\hline Fars & $3660(69.7)$ & $50.4(22.6)$ & \multirow[t]{5}{*}{0.560} \\
\hline Turk & $571(11.0)$ & $50.5(22.8)$ & \\
\hline Lor & $460(8.26)$ & 49.4(23.3) & \\
\hline Kurd & $350(6.7)$ & $49.0(22.7)$ & \\
\hline Others & $210(4.0)$ & $52.2(23.2)$ & \\
\hline
\end{tabular}

There was a significant correlation between the SES level and trust in the healthcare system ( $P$ value $<0.001)$. There was also a negative linear correlation $(r=-0.21$, P-value $<0.001)$ between trust and 
perceived fear (Figure 1).

Based on the multivariable modeling, the SES level (RC, $-3.43 ; 95 \% \mathrm{Cl}:-3.63,-3.21)$ and perceived fear of COVID-19 (RC, $-2.13 ; 95 \% \mathrm{Cl}:-3.00,-1.22$ ) have statistically significant correlations with trust in the healthcare system (Table 2).

Table 2. Correlates of Public Trust in the Healthcare System during the COVID-19 Epidemic in Iran

\begin{tabular}{|llll|}
\hline Characteristics & $\begin{array}{l}\text { Crude Coef. } \\
(95 \% \mathrm{Cl})\end{array}$ & $\begin{array}{l}\text { Adjusted Coef. } \\
(95 \% \mathrm{Cl})\end{array}$ & P-value \\
\hline Higher SES (Deciles) & $-3.46(-3.65,-3.27)$ & $-3.43(-3.63,-3.21)$ & $<0.001$ \\
\hline Gender (Ref.: Female) & $-1.58(-3.12,-0.04)$ & $-1.82(-3.00,-0.62)$ & 0.006 \\
\hline Higher Education (Level) & $-1.62(-2.27,-0.97)$ & $-1.52(-2.13,-0.92)$ & $<0.001$ \\
\hline Information source (Ref.: Inside Iran) & $-5.18(-6.33,-4.01)$ & $-5.65(-6.96,-4.32)$ & $<0.001$ \\
\hline Perceived Fear (ref.: Less than median) & $-5.01(-5.84,-4.18)$ & $-2.13(-3.00,-1.22)$ & $<0.001$ \\
\hline Constant & $50.32(49.11,51.54)$ & $83.14(78.98,87.3)$ & - \\
\hline
\end{tabular}

\section{Discussion}

In this national rapid assessment conducted in the time of the COVID-19 epidemic in Iran, we estimated the average level of public trust in Iran's healthcare system to be around $50 \%$. Furthermore, our estimate for the average level of the public's perceived fear was more than $70 \%$. Trust in the healthcare system and perceived fear varied across subpopulations. Individuals with higher SES reported lower levels of trust, and at the same time higher levels of perceived fear. Men and participants with higher levels of education reported lower levels of trust. Individuals with higher levels of perceived fear had less trust in the healthcare system.

The average score of public trust in the healthcare system in our study, although roughly equal to that estimated by Tabrizi et. al. in Tabriz in 2013[18], is significantly lower than the same parameter in developed countries[11, 19,20]. However, a study in China has shown that only about $28 \%$ of Chinese have complete confidence in their healthcare system[17]. According to a study in Spain, most people believe that the health system is not trustable and needs to undergo radical changes [21].

Studies in various countries have shown that the level of public trust in national healthcare systems has been declining $[10,12,22]$. However, the level of trust in this study is approximately equal to that of seven years ago in northwestern Iran[18]. This may indicate the relative stability of the level of trust in the healthcare system in Iran even though the Iranian healthcare system has experienced a serious reform during these years[23]. Studies have shown, however, that levels of trust in healthcare systems have usually only been slightly affected by changes in the healthcare system alone; therefore, this might not be 
a good indicator of healthcare system's performance[24]. Some authors have argued that indicators stemming from the structure of governance and community culture are at the root of public trust in the healthcare system [25-28].

Although in the context of the COVID-19 epidemic, a high level of public trust could provide many useful resources for management and control of the epidemic[19, 25], we showed that it is not at an acceptable and supportive level in Iran; Therefore, during the epidemic period in Iran, it is necessary to make decisions with complete caution, and anticipation of a low rate of public compliance and support[4].

Although the current level of trust in the healthcare system might not be helpful in controlling the COVID19 epidemic in Iran, this situation can be an opportunity to rebuild trust in the healthcare system[1, 12]. In some studies it is illustrated that the level of public trust in the healthcare system has also been, to some extent, dependent on recent behaviors and triumphs of the same healthcare system [5, 12, 13, 25, 29]; therefore, the relative successes of the healthcare system in COVID-19 epidemic control may be a good opportunity to improve public trust in the healthcare system. In line with the immediate or medium-term rebuilding of public trust in the healthcare system, it is essential that the Iranian healthcare system, designs and implements a rigorous, transparent and honest strategy for communicating with the public about the COVID-19 epidemic, in addition to careful planning based on scientific evidence, and the selection of the most appropriate policies adopted by the public $[6,12,30,31]$.

Although it is possible to rebuild public trust in the healthcare system, implementing robust strategies is of vital importance[4]. Research to identify the underlying causes of mistrust should be strengthened and appropriate approaches must be designed based on the resultant evidence $[4,26]$. Researchers have shown that, compared to mistrust caused by policy ambiguity, mistrust resulting from the incompetency of the healthcare system could be repaired by simpler strategies[27].

In rebuilding public trust in the healthcare system, it is important to note that in developing countries, such as Iran, one of the main levels of governance is dealing with people through the healthcare system; therefore, the functioning of the healthcare system in addition to trust in the healthcare system will also be directly related to trust in the government [28]. On the other hand, the performance of other parts of the government can also severely affect the trust in the healthcare system [21, 28]. Consequently, the Ministry of Health of Iran needs to actively lobby for the restoration of trust in the healthcare system through various methods and advocacy at all levels of government. Since trust in the healthcare system will be a serious determinant of health, any political-economic event in the country should be monitored by the Ministry of Health and reconciled with the public's trust in the healthcare system $[8,28,32]$.

In the current circumstances of the COVID-19 epidemic, one of the important reasons for the decline of public trust in the healthcare system is the numerous rumors propagated by individuals, groups, or other states with political-economic goals [3, 6]; therefore, the Iranian Ministry of Health needs urgent planning and action to identify these rumors alongside their source/s of dissemination, social origins, social influence and acceptability, and ultimately the appropriate way of communicating with the public about 
them[6, 26, 33]. Dealing with this source of mistrust properly can help rebuild trust in Iran's healthcare system[33].

Another important factor in rebuilding public trust in the healthcare system in times of health crises is the appropriate public communication about uncertainties[6,34]. People have a variety of news sources with different tendencies[26]. Moreover, in times of crisis, there is usually a lack of sufficient evidence, and as a result, policymakers' control decisions change. Sometimes some unreliable and inappropriate information can damage subgroups of the public and need to be handled appropriately[35]. In such circumstances, it is necessary to establish clear and honest communication with the public and to clarify the reasons for the decisions made regarding the crisis [6, 30, 31]. Two-way communication and listening to the public's voices can help improve public trust in Iran's healthcare system[12, 22]. To do so effectively, communicators need to receive specialized training, be selected from a variety of groups with higher social acceptability, actively engage with social influencers, provide the right environment for the public so that their voices are heard, communicate constructively and proactively with the various media, and introduce reliable news sources. All communicators must provide similar content in different ways, and policies that are probably not accurate must not be denied but must be explained to the public $[6,11-$ $13,26-30,32,33,35]$.

Our study showed that some groups with probably higher social influence, namely those with higher education and those with better SES, reported lower levels of trust in the healthcare system. Although various studies have reported conflicting results on the impact of the social class on the trust in the healthcare system $[17,19,36,37]$, the Iranian healthcare system now needs to interact constructively with these social subgroups. In most countries, even though the level of public trust in the healthcare system at the macro level is low, public trust in service providers has been reported to be at a satisfactory level $[19,20,36]$. In Iran, healthcare providers and teachers have a satisfactory level of public trust[38]; therefore, the Iranian healthcare system might also need a plan for constructive communication with these groups and take advantage of their potential social influence. Such strategies are necessary to rebuild trust in the healthcare system and control the COVID-19 epidemic.

Since our study used a single question approach to measure social trust in the healthcare system, an approach that has been applied repeatedly by others $[17,28]$, it did not measure the six recommended dimensions of public trust in the healthcare system[20]. However, this was in line with the purpose of the study, namely to rapidly assess the overall level of trust in the healthcare system at the early phase of the COVID-19 epidemic in Iran. Moreover, measuring the various dimensions of trust in the healthcare system at the time of the COVID-19 epidemic would not provide more information than measuring the overall level of trust[19], on the other hand, it was not possible in almost a short time. This study is the first national-level study in Iran to measure public trust in the healthcare system.

\section{Conclusions}


At the time of the COVID-19 epidemic in Iran, the level of trust in the healthcare system is not acceptable and supportive. Urgent actions are needed to promote public trust in the healthcare system. People with higher social class had the lowest levels of trust in the healthcare system. Further studies are needed to identify the reasons for the low level of public trust in the Iranian healthcare system.

\section{List Of Abbreviations}

$\mathrm{AE}$, academic education

$\mathrm{RC}$, regression coefficient

$\mathrm{Cl}$, confidence interval

SD, standard deviation

SES, socioeconomic status

MCA, multiple correspondence analysis

ANOVA, one-way analysis of variance

\section{Declarations}

\section{Ethics approval and consent to participate}

Informed consent has been obtained from each participant. This study has been approved by the Ethics Committee of the Shiraz University of Medical Sciences, Shiraz, Iran (code of ethics IR.SUMS.MED.REC.1399.301).

\section{Consent for publication}

Not applicable.

\section{Availability of data and materials}

The datasets used and analyzed during the current study are available from the corresponding author on reasonable request.

\section{Competing interests}

$\mathrm{KBL}$ is an ex-health minister in Iran. MHI, is an ex-president of Shiraz University of Medical Sciences. Authors declare no conflict of interests. 


\section{Funding}

This study is funded by Shiraz University of Medical Sciences. The funding agency had no role in the design of the study, the collection, analysis, and interpretation of data and in writing the manuscript.

\section{Authors' contributions}

$\mathrm{KBL}$ and $\mathrm{HMV}$ contributed to the design of the study. $\mathrm{KBL}, \mathrm{HMV}, \mathrm{AHH}$ and $\mathrm{MHI}$ contributed to the implementation and analysis plan. HMV has written the first draft of this manuscript and all authors have read the text and contributed with inputs and revisions, and all authors read and approved the final manuscript.

\section{Acknowledgements}

We are extremely grateful to all women who took part in this study.

The project was part of HMV's postgraduate study in health policy at Shiraz University of Medical Sciences.

\section{References}

1. Gilles I, Bangerter A, Clémence A, Green EG, Krings F, Staerklé $C$, Wagner-Egger P: Trust in medical organizations predicts pandemic (H1N1) 2009 vaccination behavior and perceived efficacy of protection measures in the Swiss public. European journal of epidemiology 2011, 26(3):203-210.

2. Vardanjani HM, Heydari ST, Dowran B, Pasalar M: A cross-sectional study of Persian medicine and the COVID-19 pandemic in Iran: Rumors and recommendations. Integrative medicine research 2020, 9(3):100482.

3. Böl GF: Risk communication in times of crisis. EMBO reports 2016, 17(1):1-9.

4. Gille F, Smith S, Mays N: Why public trust in health care systems matters and deserves greater research attention. Journal of health services research \& policy 2015, 20(1):62-64.

5. Lee K: How the Hong Kong government lost the public trust in SARS: Insights for government communication in a health crisis. Public Relations Review 2009, 35(1):74-76.

6. J. Holmes B, Henrich N, Hancock S, Lestou V: Communicating with the public during health crises: experts' experiences and opinions. Journal of Risk Research 2009, 12(6):793-807.

7. Bangerter A, Krings F, Mouton A, Gilles I, Green EG, Clemence A: Longitudinal investigation of public trust in institutions relative to the 2009 H1N1 pandemic in Switzerland. PLoS One 2012, 7(11).

8. Gille F, Smith S, Mays N: Towards a broader conceptualisation of 'public trust'in the health care system. Social theory \& health 2017, 15(1):25-43. 
9. Gille F, Smith S, Mays N: What is public trust in the healthcare system? A new conceptual framework developed from qualitative data in England. Social Theory \& Health 2020:1-20.

10. Chanley VA, Rudolph TJ, Rahn WM: The origins and consequences of public trust in government: A time series analysis. Public opinion quarterly 2000, 64(3):239-256.

11. van Der Schee E, Braun B, Calnan M, Schnee M, Groenewegen PP: Public trust in health care: a comparison of Germany, the Netherlands, and England and Wales. Health Policy 2007, 81(1):56-67.

12. Larson HJ, Heymann DL: Public health response to influenza $A(\mathrm{H} 1 \mathrm{~N} 1)$ as an opportunity to build public trust. Jama 2010, 303(3):271-272.

13. Vaughan $E$, Tinker $T$ : Effective health risk communication about pandemic influenza for vulnerable populations. American Journal of Public Health 2009, 99(S2):S324-S332.

14. Farzadfar F, Murray CJ, Gakidou E, Bossert T, Namdaritabar H, Alikhani S, Moradi G, Delavari A, Jamshidi $H$, Ezzati M: Effectiveness of diabetes and hypertension management by rural primary health-care workers (Behvarz workers) in Iran: a nationally representative observational study. The Lancet 2012, 379(9810):47-54.

15. Takian A, Raoofi A, Kazempour-Ardebili S: COVID-19 battle during the toughest sanctions against Iran. The Lancet 2020.

16. Gandomkar A, Poustchi H, Moini M, Moghadami M, Imanieh H, Fattahi MR, Ayatollahi SMT, Sagheb MM, Anushiravani A, Mortazavi R: Pars cohort study of non-communicable diseases in Iran: protocol and preliminary results. International journal of public health 2017, 62(3):397-406.

17. Zhao D, Zhao H, Cleary PD: Understanding the determinants of public trust in the health care system in China: an analysis of a cross-sectional survey. Journal of health services research \& policy 2019, 24(1):37-43.

18. Tabrizi J, Saadati M, Sadeghi Bazargani H, Abedi L, Alibabayee R: Iranian public trust in health services: evidence from Tabriz, Islamic Republic of Iran. EMHJ-Eastern Mediterranean Health Journal 2016, 22(10):713-718.

19. Calnan MW, Sanford E: Public trust in health care: the system or the doctor? BMJ Quality \& Safety 2004, 13(2):92-97.

20. Straten GF, Friele RD, Groenewegen PP: Public trust in Dutch health care. Social science \& medicine 2002, 55(2):227-234.

21. Jovell A, Blendon RJ, Navarro MD, Fleischfresser C, Benson JM, DesRoches CM, Weldon KJ: Public trust in the Spanish health-care system. Health Expectations 2007, 10(4):350-357.

22. Brook RH: Health policy and public trust. JAMA 2008, 300(2):211-213.

23. Bahadori M, Ravangard R, Alimohammadzadeh K, Hosseini SM: Plan and road map for health reform in Iran. Bmj 2015, 351:h4407.

24. Schee Evd, Groenewegen PP, Friele RD: Public trust in health care: a performance indicator? Journal of Health, Organisation and Management 2006, 20(5):468-476. 
25. Legido-Quigley H, Asgari N, Teo YY, Leung GM, Oshitani H, Fukuda K, Cook AR, Hsu LY, Shibuya K, Heymann D: Are high-performing health systems resilient against the COVID-19 epidemic? The Lancet 2020, 395(10227):848-850.

26. Bangerter $A$ : Investigating and rebuilding public trust in preparation for the next pandemic. In.: Hogrefe Publishing; 2014.

27. Poppo L, Schepker DJ: Repairing public trust in organizations. Corporate Reputation Review 2010, 13(2):124-141.

28. Rockers PC, Kruk ME, Laugesen MJ: Perceptions of the Health System and Public Trust in Government in Low and Middle-Income Countries: Evidence from the World Health Surveys. Journal of health politics, policy and law 2012, 37(3):405-437.

29. Ozawa S, Paina L, Qiu M: Exploring pathways for building trust in vaccination and strengthening health system resilience. BMC health services research 2016, 16(7):639.

30. Menon K, Goh KT: Transparency and trust: risk communications and the Singapore experience in managing SARS. Journal of Communication Management 2005, 9(4):375-383.

31. Fung IC-H, Tse ZTH, Chan BSB, Fu K-W: Middle East respiratory syndrome in the Republic of Korea: transparency and communication are key. Western Pacific surveillance and response journal: WPSAR 2015, 6(3):1.

32. Allsop J: Regaining trust in medicine: Professional and state strategies. Current Sociology 2006, 54(4):621-636.

33. Birman KP: The surprising power of epidemic communication. In: Future directions in distributed computing. edn.: Springer; 2003: 97-102.

34. Vinck P, Pham PN, Bindu KK, Bedford J, Nilles EJ: Institutional trust and misinformation in the response to the 2018-19 Ebola outbreak in North Kivu, DR Congo: a population-based survey. The Lancet Infectious Diseases 2019, 19(5):529-536.

35. Gesser-Edelsburg A, Mordini E, James JJ, Greco D, Green MS: Risk communication recommendations and implementation during emerging infectious diseases: a case study of the $2009 \mathrm{H} 1 \mathrm{~N} 1$ influenza pandemic. Disaster medicine and public health preparedness 2014, 8(2):158-169.

36. Blendon RJ, Benson JM, Hero JO: Public trust in physicians-US medicine in international perspective. N Engl J Med 2014, 371(17):1570-1572.

37. Zhao D, Zhao H, Cleary PD: International variations in trust in health care systems. The International journal of health planning and management 2019, 34(1):130-139.

38. Rahimpour L, Garousi S, Maghsoodi S: Trust in physician, satisfaction with physician and their relationship among diabetic patients in Kerman, Iran. Journal of Research and Health 2018, 8(4):373381.

\section{Figures}




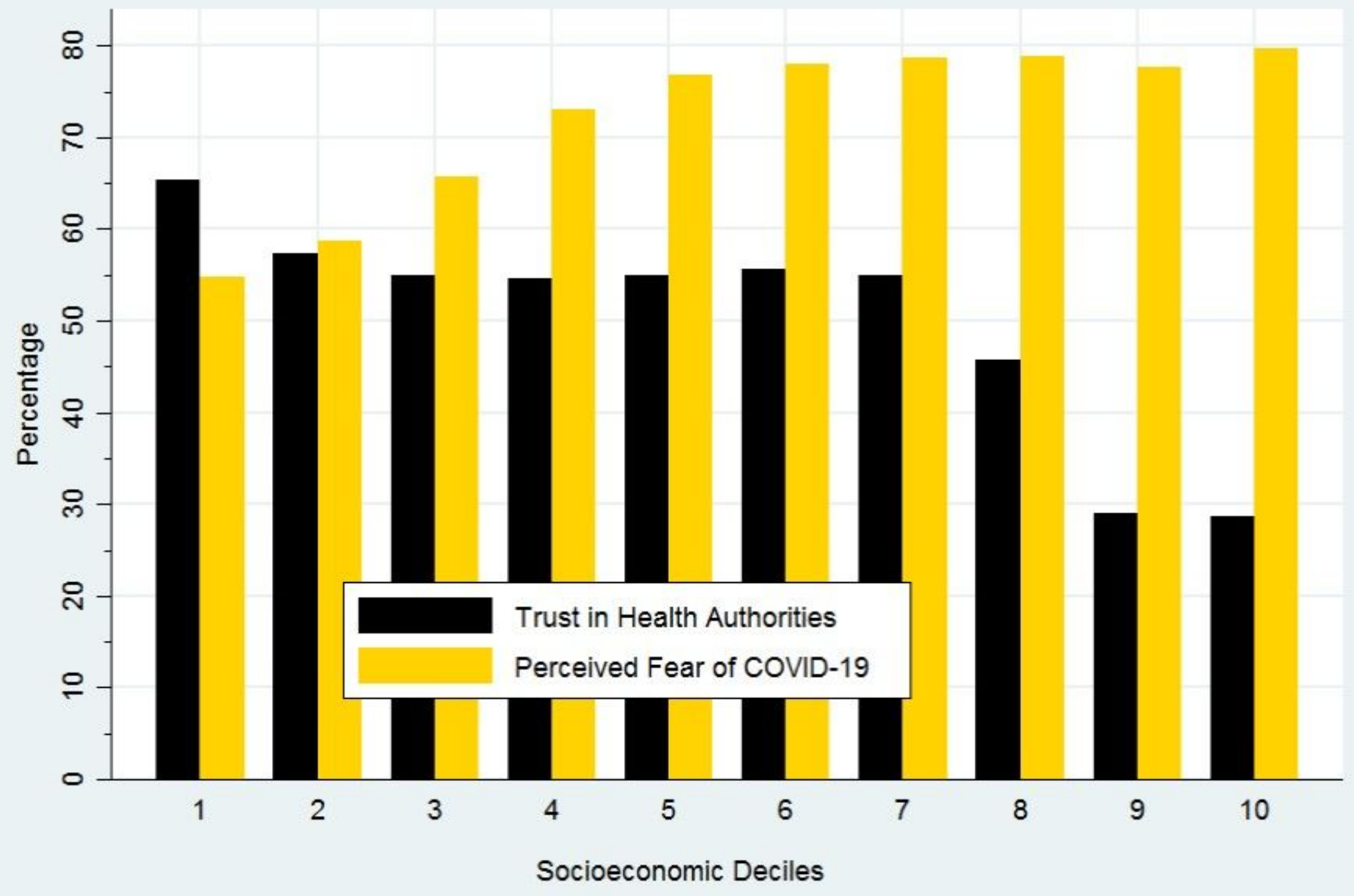

Figure 1

Correlation of Socioeconomic Status and Public Trust in the Healthcare System during the COVID-19 Epidemic in Iran 


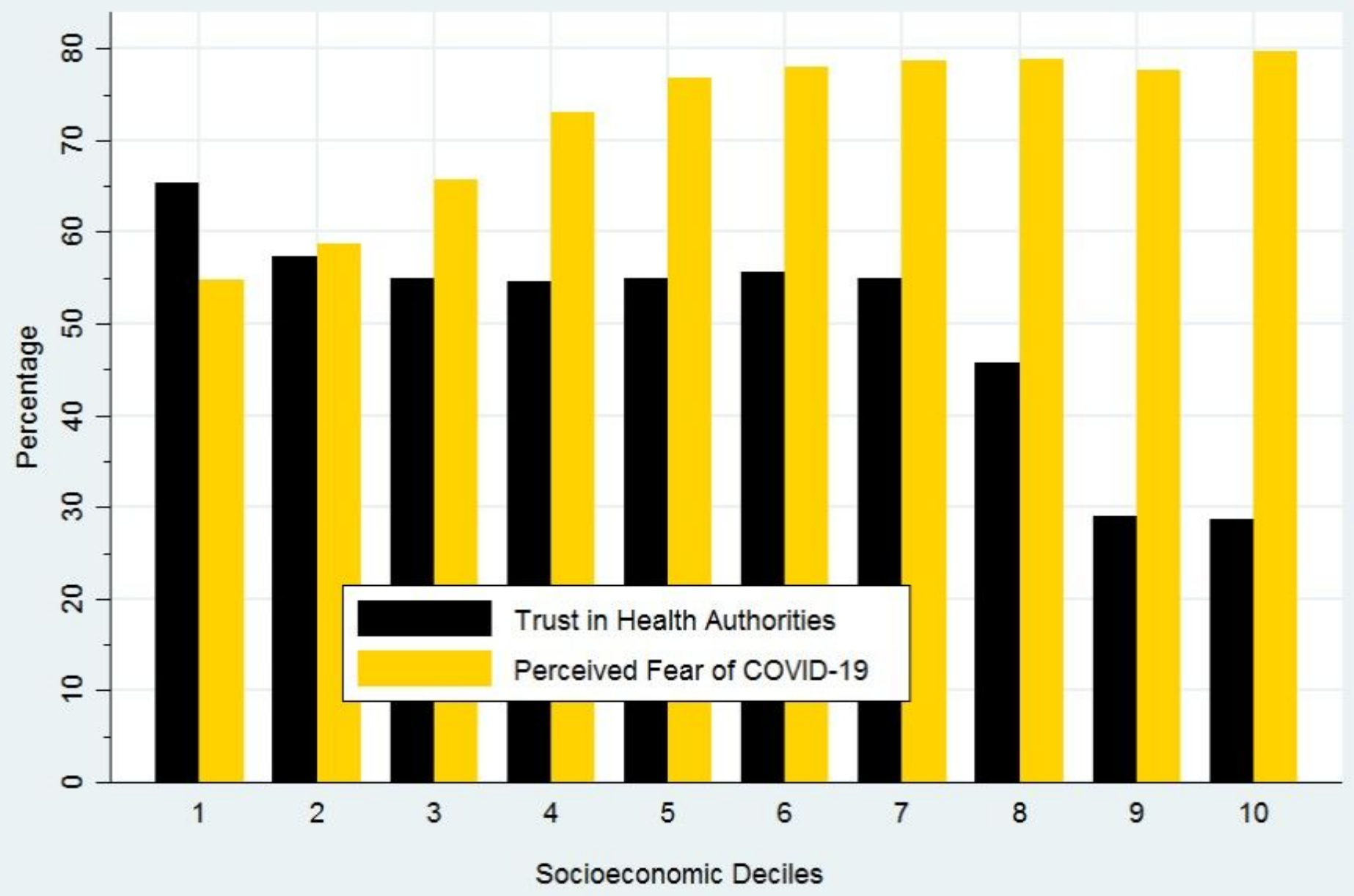

Figure 1

Correlation of Socioeconomic Status and Public Trust in the Healthcare System during the COVID-19 Epidemic in Iran 